\title{
Tráfico caravanero y arriería colonial en el siglo $\mathrm{XVI}^{1}$
}

Cecilia Sanhueza

\section{Introducción}

El desarrollo de la actividad arriera en Atacama constituye un fenómeno específico dentro del proceso que se genera a partir del siglo XVI en esa región. Sin embargo es, a la vez, un referente que nos permite visualizar y problematizar, desde una perspectiva más amplia, ciertos elementos de la sociedad indígena atacameña y las transformaciones o readaptaciones que pudo sufrir a través del Período Colonial.

Se ha generalizado en nuestra historiografía latinoamericana la percepción de una población indígena pasiva, víctima o -por lo menos- simple receptora de los cambios producidos a partir de la instauración del sistema hispano-colonial. En este sentido, la investigación etnohistórica andina, ha permitido ir cuestionando las interpretaciones tradicionales no sólo por sus aportes en el conocimiento de las poblaciones existentes al momento del contacto, sino por replantear el rol que éstas desempeñaron a través de nuestra historia americana (Pease 1986).

Al iniciarse la colonia, comenzó un largo proceso de consolidación de un nuevo sistema económico, social y político. Una nueva cultura presionaba por penetrar en las sociedades indígenas y por plasmar en todos sus niveles -especialmente en el económico- una racionalidad y una estructura mercantil. El aparato colonial se sustentaba en la fuerza de trabajo indígena y la imposición del tributo constituía el mecanismo más eficaz para insertar a esta población en el sistema. Sin lugar a discusión, estos trastornos repercutieron fuertemente en la sociedad andina. Se ha planteado que ello provocó un rápido e irreversible proceso de desestructuración (Wachtel 1973). Esta interpretación, que consideramos válida -sobre todo a nivel de las grandes estructuras hegemónicas que no pudieron sobrevivir a la conquista- tiende, sin

1 Este artículo fue realizado en el marco del Proyecto FONDECYT 90-525, en el cual la autora es coinvestigadora. embargo, a marcar un sello sobre el Período Colonial que desconoce la dinámica social y la capacidad readaptativa de los pueblos andinos.

Un importante aporte en este sentido ha sido el enfocar la participación mercantil indígena, no solamente como respuesta a la presión española, sino también como una opción viable frente a un sistema económico que se desarrollaba progresivamente. En este sentido, la intervención mercantil pudo constituir una estrategia reproductiva más o una readecuación de estrategias tradicionales andinas (Platt 1987).

La arriería colonial en Atacama representó uno de los mecanismos utilizados por la población indígena para insertarse en la nueva estructura económica y responder a sus exigencias. Pero la actividad arriera fue también un elemento integrador que contribuyó a mantener y reproducir los vínculos que históricamente se habían desarrollado entre diferentes grupos étnicos.

\section{Estrategias reproductivas andinas: Tráfico caravanero y movilidad en el espacio circumpuneño}

Uno de los elementos que ha permitido a los investigadores identificar el Area Andina, radica en ciertas manifestaciones culturales comunes, en cuanto a las formas de enfrentar y utilizar la naturaleza, en un medio ecológico de condiciones muy particulares y a veces extremas. Por encima de las diferencias regionales, se percibe una racionalidad económica compartida, que se expresa en la materialización de diferentes patrones de complementariedad.

Al modelo inicial de "archipiélago vertical" o de acceso a un máximo de pisos ecológicos, propuestos por Murra (1975), se han sumado aportes que enriquecen y complejizan el concepto de complementariedad. La dinámica interna de cada colectividad, el intercambio y en general las relaciones entre distintos grupos que interactúan y complementan recursos y bienes, nos llevan a plantear este fenómeno no sólo desde una 
perspectiva ecológica, sino fundamentalmente social e histórica. Entendemos por patrón de complementariedad al conjunto de estrategias políticas, sociales y económicas, implementadas por una colectividad determinada para procurarse el acceso a recursos y productos de diferentes medio ambientes, que son considerados como necesarios para su reproducción. En este sentido, la complementariedad constituye no sólo una respuesta al medio natural, sino sobre todo, un producto social, generado por grupos humanos que en el curso de sus propios procesos históricos renuevan y redefinen sus estrategias reproductivas (Salomon 1985; Martínez 1990).

De acuerdo a esto, comenzaremos por describir muy someramente aquellos elementos que nos permiten contextualizar el espacio económico y social en que se insertaba la región atacameña en el período prehispánico, y establecer las características generales de los grupos que allí interactuaban.

Precisar lo que podría ser el territorio atacameño, supone ya un primer problema. Sus actuales límites, incluso los coloniales, no constituyen verdaderos indicadores de su extensión o, más bien, del tipo de ocupación territorial de los grupos humanos que allí habitaban, puesto que el espacio por ellos ocupado transgredía los límites establecidos por la administración española y las supuestas fronteras naturales. Es necesario, entonces, recurrir a categorías de análisis aportadas por la antropología y la arqueología.

\section{La Subárea Circumpuneña}

Se la ha definido como aquella que se extiende a partir del sur del Salar de Uyuni, abarcando el altiplano de Lípez, la Puna de Jujuy y la Puna de Atacama hasta aproximadamente el paso San Francisco. Integra, además, las vertientes cordilleranas oriental y occidental que bordean las tierras altas. Estos "bordes", cuyas delimitaciones son muy imprecisas, abarcan por el occidente el desierto -incluyendo el litoral y los oasis y quebradas piemontanos- desde el norte del río Loa hasta Chañaral. Por el oriente desde las cabeceras y valles de la región de Humahuaca hasta el borde chaqueño, incluyendo más al sur las cercanías de los valles de Jujuy y Salta (Aldunate y Castro 1981: 12-13).

El espacio andino en general, y en particular la Subárea Circumpuneña -abarcando costa, quebradas, precordillera y puna- no constituye, evidentemente, un todo homogéneo en términos ecológicos y étnicos. Sin embargo, es justamente la dinámica de la interacción de grupos humanos distintos y de la utilización de recursos productivos diferenciados distribuidos a través de su geografía, lo que otorga a nuestra región el carácter de conjunto integrado.

Se ha definido a esta subárea como una región de "frontera blanda", que si bien se articuló en alguna medida a los complejos de desarrollo de otras regiones (p.e., Tiwanaku, "señoríos altiplánicos", incas) experimentó a su vez, procesos diferenciales (Tarragó 1984).

En cuanto a las alternativas de producción y recolección en los distintos estratos y ecozonas de la subárea, existía una rica diferenciación. El Loa Medio e Inferior, la cuenca del Salar de Atacama y la quebrada de Tarapacá ofrecían tierras aptas para la explotación de una agricultura subtropical en sus valles, además de recursos forestales y frutales en la Pampa del Tamarugal y oasis del Salar. A ello se sumaba el acceso y explotación de recursos marinos en la costa. En el borde oriental circumpuneño, las cabeceras de las quebradas de Humahuaca y del Toro, permitían el desarrollo de una actividad agropecuaria que se articulaba con los valles más bajos y las tierras tropicales orientales (Tarragó 1984). La ganadería representaba una actividad fundamental y común a todas las poblaciones de la subárea. El camélido, esencial en la economía andina, tanto por sus subproductos como por su capacidad de carga, desempeñaba un rol determinante en la movilidad de estos pueblos. De allí la importancia de la Puna, que con sus recursos forrajeros permanentes, articulaba y complementaba las economías de las regiones circundantes. No sólo constituía una región de paso, sino una fuente de vida para el ganado y, por tanto, para los hombres. Secundariamente la región puneña ofrecía una potencialidad agrícola para cultivos especializados como los tubérculos y la quínoa, junto con la extracción de recursos mineros (Núñez y Dillehay 1979).

Una característica fundamental de nuestra área es la capacidad de sus habitantes de satisfacer sus necesidades a través de una constante movilidad. En el Area Andina en general, el aprovechamiento de múltiples estratos o pisos ecológicos constituye un patrón común. Como respuesta a la baja potencialidad del medio para una agricultura extensiva, la dispersión de los recursos forrajeros y la variedad relativamente limitada de recursos productivos que 
ofrece cada uno de los niveles o nichos altitudinales, las sociedades andinas fueron desarrollando diferentes estrategias de complementariedad.

En la Subárea Circumpuneña, desde períodos tempranos, un patrón de alta movilidad alternó el control directo de distintos espacios productivos con un activo tráfico de intercambio, que permitió optimizar el acceso y circulación de bienes a través de grandes distancias. A lo largo del período prehispánico, un conjunto de circuitos y rutas de desplazamiento de caravanas de llamas, fue dibujándose y redibujándose en el espacio circumpuneño de acuerdo a las necesidades, influencias y procesos históricos que sufrían las poblaciones del área (Núñez y Dillehay 1979).

A pesar de las diversidades étnicas y de la existencia de estructuras sociopolíticas aparentemente autónomas, se intercambiaban y movilizaban bienes de consumo y materias primas de distinta índole: productos agropecuarios, minerales, manufacturas y diferentes especies de pesca y recolección marina. Estos circuitos integraban, además, nuevas tecnologías y corrientes ideológicas. Especies de distinta procedencia registradas arqueológicamente en el norte de Chile, tales como: plumas tropicales, utensilios para el consumo de alucinógenos no recolectados localmente, evidencias de coca en distintos sitios de valles y costa desértica, conchas del Pacífico en los oasis de Atacama y en el Noroeste Argentino, y, en general, cerámicas y metales de procedencia exótica; se suman a la constante presencia de aparejos para carga de llamas y a toda una infraestructura asociada a rutas de caravanas, como son la red de geoglifos diseminados a través del desierto y los lugares de culto que no presentan características de ocupación estable (Núñez 1976; Tarragó 1984).

En ese contexto, el tráfico de caravanas representaba una modalidad más dentro de las múltiples estrategias de complementariedad desarrolladas por estos pueblos. La energía animal cumplía un rol fundamental, por ello, el tráfico no se puede desvincular de la actividad ganadera propiamente tal. Volveremos a este punto más adelante.

\section{Los grupos étnicos y su distribución espacial}

Intentar definir cuáles eran los grupos que habitaban la subárea al iniciarse el Período Colonial, y cual era el territorio que ocupaban, requiere de mucha prudencia. A medida que el conocimiento etnohitórico va desarrollándose, las características del poblamiento del espacio circumpuneño presentan mayores niveles de complejidad.

En general, las primeras crónicas españolas tendían a adjudicar a los diferentes grupos o "naciones" que encontraban a su paso, una determinada territorialidad que, en muchos casos, no reflejaba el verdadero carácter de su organización espacial. De allí que muchas veces el trazado de las nuevas jurisdicciones administrativas y de los repartimientos, no siempre coherentes con la realidad, presentaran dificultades tanto para la población andina como para las autoridades y encomenderos españoles (Saignes 1986).

En nuestra subárea, a medida que fue consolidándose el proceso de colonización, se constituyeron los corregimientos de Anca, Lípez, Chichas, Tucumán y Atacama. Sin embargo, en general, cada uno de estos corregimientos presentaba más de una unidad étnica, a la vez que cada unidad étnica ocupaba territorios que desbordaban aquellos límites coloniales. Podemos distinguir una serie de grupos que en mayor o menor medida se relacionaban e interactuaban al iniciarse la colonia y que describiremos muy sucintamente.

En el borde norte circumpuneño, los llamados indios lipes ocupaban preferentemente el altiplano que se extendía a partir del sur del Salar de Uyuni. Desde tiempos prehispánicos este grupo parece haber ido penetrando parte de la Puna de Jujuy, a la vez que las regiones del Alto y Medio Loa en lo que posteriormente fue territorio del corregimiento de Atacama (Martínez et al. 1988). El altiplano de Lípez, donde se encontraba el grueso de la población, determinó un énfasis ganadero que adquirió un gran desarrollo. A través de los períodos Colonial y Republicano, este grupo se destacó por su gran movilidad y activas relaciones de intercambio no sólo con Atacama sino también con las poblaciones de Tarapacá y de Tucumán.

También en el extremo sur del altiplano, pero hacia el este de los lipes, los chichas ocupaban tanto territorios puneños como valles intermedios y tierras bajas de la precordillera de Tarja. Aunque en términos generales el territorio ocupado por los chichas correspondió a lo que después constituyó el corregimiento del mismo nombre, este grupo parece haber abarcado también tierras "yungas" y sectores de los bordes más meridionales de la Puna de Jujuy (Saignes 1986). 
Respecto al borde oriental circumpuneño, los antecedentes que tenemos para el siglo XVI son bastante pobres, debido a la constante resistencia que su población mantuvo frente a los intentos de dominación hispana. La variedad de grupos, o al menos de denominaciones étnicas en esa región, es amplia (Sánchez y Sica 1990). Nos referiremos exclusivamente a aquellos que sabemos que mantenían contacto con los atacamas.

Los omaguacas, asentados en la quebrada del mismo nombre (Humahuaca), estaban distribuidos en distintas parcialidades. Al parecer, controlaban territorios de puna y valles de tierras más bajas. La ganadería parece haber sido una de sus actividades más importantes (Lozano Machuca 1885 [1581]; Sánchez y Sica 1990).

Los casabindos y cochinocas, que no sabemos si constituían un mismo grupo étnico, pero que en la información colonial suelen aparecer relacionados, habitaban sectores de la puna vecina a la Quebrada de Humahuaca y explotaban fundamentalmente los recursos ganaderos de la región.

Respecto a los denominados apatamas, también de hábitat puneño, no existe mayor claridad sobre su identidad étnica ni de las características específicas de su distribución territorial (Krapovickas 1978).

La documentación del siglo XVI, relativa al noroeste argentino, menciona también núcleos de población provenientes de Atacama, quienes se encontraban en esas regiones con sus caciques realizando actividades agroganaderas, situación que continuó durante los siglos XVII y XVIII (Martínez 1990). Las relaciones entre los atacamas y el resto de los grupos locales parecen haber sido estrechas. En la segunda mitad del siglo XVI, Francisco Altamirano, hijo del encomendero de Atacama se dirigía al "ualle de omaguaca casauindo e jujuy" a pacificar a los indios omaguacas, apatamas, casabindos, cochinocas, calchaquíes y atacamas que se habían "aliado y convocado en uno", bajo el liderazgo de don Diego Viltipoco -natural de Atacama- y que se hallaban "fortalecidos" en el valle de Humahuaca (AGI 1596, fs. 41v-42).

Respecto a la población que ocupaba el borde sur de la región de Tarapacá, y que según la investigación arqueológica y etnohistórica podemos considerar como parte integrante de la Subárea Circumpuneña, presenta todavía muchas dudas respecto a su filiación étnica. Al parecer, como expresa un documento de 1562, los indígenas de Pica y Tarapacá habrían pertenecido a "una sola nazion y lenguaje" (AGI 1562, f 103). Durante el siglo XVII, se ha documentado también la presencia de poblaciones altiplánicas en esa región (Odone 1991Ms).

En la vertiente occidental meridional, correspondiente a nuestra región de Atacama, podemos distinguir la presencia de, al menos, tres grupos étnicos.

En el litoral encontramos una población pescadorarecolectora que habitaba y se desplazaba a través de las costas del Pacífico. La población que en el siglo XVI fue encomendada en la costa de Atacama, aparece en la documentación con el nombre de "camanchaca" y fue siempre diferenciada étnicamente de la población del interior de la región (AGI $n^{\circ}$ 92, 1644, f. 71v).

En relación a esta última, desde el período prehispánico tardío, podemos distinguir dos grandes complejos culturales: uno perteneciente a la tradición atacameña o "Tradición del Desierto" y otro nítidamente altiplánico, predominante el primero en los oasis de pie de Puna y el segundo en las quebradas altas del Loa Superior (Castro et al. 1984).

Se ha denominado, etnohistóricamente, "atacamas" a aquel grupo que en el siglo XVI se concentraba demográficamente en las dos hoyas hidrográficas de la región: la cuenca del Loa y los oasis del Salar de Atacama, además de la Puna aledaña.

La densidad de población en Atacama, parece haber sido considerable. En 1581, el Factor de Potosí mencionaba una cantidad de alrededor de 2000 indígenas (Lozano Machuca 1885 [1581]: XXV). Si consideramos las características extremadamente áridas de la región, estos cálculos, aunque muy aproximativos, permiten suponer una productividad alimenticia bastante alta. De hecho, los españoles percibieron tempranamente el rol estratégico de la región como centro de reabastecimiento. Esta situación no era nueva. Atacama había constituido, desde tiempos prehispánicos, un eje de particular importancia del tráfico interregional. Sobre todo la región de los oasis del Salar, en la cual convergían rutas provenientes de la costa, del norte y sur desértico y del otro lado de la cordillera. Esta condición de "centro neurálgico del tráfico interregional” (Berenguer 1984: 18), requería de una producción excedentaria que además de satisfacer las necesidades locales, permitiera la 
realización del intercambio. Ello fue posible gracias al desarrollo de una tecnología agrícola y ganadera capaz de explotar, racional y eficazmente, todos aquellos recursos que el desierto y sus dispersos microambientes proporcionaban. Los atacamas ocuparon todos los nichos productivos que se distribuían a través de la gradiente occidental de la Cordillera de los Andes, cultivando en sus distintos niveles el maíz, las habas y los tubérculos, y en las tierras más altas la quínoa. En los oasis, los recursos forestales y frutales de los bosques de algarrobos y chañares tuvieron también una importancia considerable en la economía local y en el intercambio.

Los pastos para el ganado -que se criaba en abundancia en la región- se distribuían también en tierras altas y bajas, lo que determinó la necesidad del desplazamiento estacional de los pastores hacia las vegas de altura.

Los atacamas, que constituían el grueso demográfico de esta región, compartían ciertos sectores de ese territorio con grupos de origen altiplánico, los que fueron asentándose allí durante el período prehispánico tardío, e interactuando en alguna medida con la población local. Esta población altiplánica que, al menos en el Período Colonial podemos identificar como provenientes de la región de Lípez, aparecen registrados en la documentación, no sólo en sectores de vegas altas, sino también ocupando temporal o permanentemente recursos agroganaderos del Loa Medio (Martínez 1990: 16-18).

De la lectura de Bibar, se desprende que los atacamas, además, mantenían fluidas comunicaciones con chichas, picas, guatacondos y copiapoes, pero no sabemos si estos grupos explotaban directamente recursos en la región. Posteriormente, la documentación del siglo XVIII, menciona una cantidad significativa de originarios de Tarapacá en este corregimiento (Bibar 1966 [1558]: 12; Martínez et al. 1988: 57-58).

Finalmente, como ya se ha dicho, el hábitat de los atacamas abarcaba también sectores de alta Puna y del Noroeste Argentino.

De manera que, para una primera aproximación histórica a la región de Atacama, es indispensable situarla dentro de un contexto regional muy amplio. La Subárea Circumpuneña constituyó un espacio económico y social donde interactuaban diferentes grupos étnicos, que a través del proceso prehispánico, fueron generando determinados patrones de movilidad, de intercambio y de explotación de recursos. Dentro de este espacio se movilizaban no sólo excedentes productivos, sino también elementos ideológicos y tecnológicos. Aunque no conocemos sus características específicas, podemos afirmar que existían mecanismos y pautas comunes de conducta social que sustentaban y en alguna medida regulaban esa interacción. En ese contexto, los atacamas alternaban el usufructo directo de recursos distantes con el tráfico de caravanas e intercambio con otros grupos ubicados, en algunos casos, a grandes distancias.

\section{La instauración del sistema colonial. La nueva organización del espacio}

$\mathrm{Al}$ iniciarse el Período Colonial, una nueva racionalidad sustentada en una concepción mercantil de la economía, presionaba por imponerse en el mundo andino. La producción, la circulación, la propiedad, los valores de uso y los valores de cambio se enmarcan en criterios drásticamente diferentes a aquellos que operaban en las sociedades indígenas. Los cambios que comienzan a producirse involucran distintas esferas de la vida económica colonial. Una de sus manifestaciones está en el proceso de reorganización territorial de las actividades productivas y de la circulación de bienes. La minería adquiere un rol preponderante en el sistema mercantil, y sus centros productivos se transforman, en gran medida, en los ejes articuladores del espacio económico colonial (Assadourian 1982).

Las minas de plata de Potosí y sus alrededores llegaron a ser un foco de absorción de mano de obra y de concentración de población, con una proporcional demanda de productos e insumos. Ello aseguraba, además, la circulación de metálico y la progresiva mercantilización de una parte de los excedentes regionales. Los circuitos de movilidad tendían a converger, en forma creciente, hacia estos enclaves y los nacientes centros urbanos.

Esta nueva configuración del espacio económico, por otra parte, determinó a su vez una regionalización político-administrativa que respondiera a sus necesidades. El carácter arbitrario de esta distribución territorial, no consideraba, en muchos casos, las dinámicas de poblamiento de las etnias andinas.

En el siglo XVI, el corregimiento de Atacama se circunscribió administrativamente a la Audiencia de Charcas, ubicada en la ciudad de la Plata. Los límites del corregimiento nunca fueron claramente 
precisados. La región fue dividida en Atacama La Alta y La Baja. La primera, también llamada La Grande, comprendía la cuenca del Salar y las tierras altas adyacentes. Tenía como cabecera y doctrina a San Pedro de Atacama y sus ayllu circundantes. $\mathrm{Al}$ oriente del Salar, los asentamientos o ayllu de Soncor, Toconao, Socaire y Peine. En el siglo XVIll se incorporaron Susques e Incahuasi. Atacama La Baja o La Chica abarcaba, por la costa, la ensenada de Cobija hasta la altura de Tocopilla hacia el norte, y de Morro Moreno hacia el sur. Al interior, la hoya del río Loa y sus afluentes, con los pueblos de Calama, Chiu Chiu -que era la cabecera y doctrina-Ayquina, Caspana y otros asentamientos que durante el Período Colonial no tuvieron el carácter de pueblo (Casassas 1974: 29-30; Paz Soldán 1978: 63).

\section{Primeras manifestaciones de la arriería colonial. El tráfico de pescado}

Impulsada por la iniciativa española, que precisaba asegurar el pago del tributo e incorporar la región al movimiento mercantil de los centros mineros del altiplano, la arriería comenzó tempranamente en Atacama. La definiremos como aquella actividad de flete o transporte de productos y/o animales, que se desarrolló en el marco mercantil colonial. En este sentido, el arriero podía desenvolverse de acuerdo a dos modalidades: como mano de obra para el transporte de mercancías pertenecientes a terceros (fletes) $o$, en cuanto iniciativa independiente, abasteciendo los mercados con excedentes productivos propios $\mathrm{o}$ adquiridos por su cuenta.

La documentación con que contamos para el siglo XVI en Atacama es aún bastante pobre. A pesar de ello, la escasa pero específica información respecto al naciente tráfico colonial de productos marinos en este corregimiento, nos entrega algunos elementos para poder caracterizar lo que podríamos llamar un período de transición entre el tráfico caravanero tradicional y la arriería colonial. En primer lugar, porque la inserción de estos arrieros en la estructura mercantil estaba, en gran medida, mediatizada por los españoles, quienes controlaban parte importante de los excedentes dirigidos a los mercados. Sin embargo, ya existía una incipiente participación de los atacamas en los centros mercantiles, que combinaba sus circuitos de intercambio con estos nuevos ejes. Por otra parte, se trata también de un período de transición, porque el "medio de producción" utilizado en los desplazamientos y transporte de carga siguió siendo el camélido, lo que implicó la adaptación de la tecnología ganadera tradicional a las nuevas necesidades.

El nuevo sistema económico en formación supo absorber y utilizar prácticas económicas ya establecidas. En el caso de Atacama, el tráfico caravanero de productos marinos fue tempranamente incorporado a los circuitos mercantiles (Martínez 1985a: 16-18). La actividad pesquera en los litorales de Arica y de Atacama llegó a cobrar gran importancia a través de todo el Período Colonial. Las costas de Atacama ofrecían una amplia variedad de especies cuyo transporte en caravanas de llamas se había convertido en una actividad económica de envergadura:

“... en aquella costa se haze grandissima pesca de congrios, tollos, lisas, dorados, armados, vagres, jureles, atunes, pulpos y otros muchos géneros de pescado... del se llevan grandes recuas de carneros a Potosí, Chuquisaca, Lípez y a todas aquellas provincias de la tierra de arriba, porque es trato principal de aquella tierra, con que an enriquecido muchos" (Vásquez de Espinoza 1948 [1628]: 617-618).

Según nuestra información, el primer español que se dedicó a esta actividad en la región fue Juan Velázquez Altamirano, encomendero de Atacama, quien además sustentó por varios períodos consecutivos el cargo de corregidor.

Un documento publicado por Martínez sobre el tráfico de pescado en 1591 desde Atacama a Potosí, nos revela algunos aspectos de las actividades de este español en la región. Por esa fecha el capitán Juan de Segura, recién nombrado corregidor, se encontraba con un ambiente hostil debido a la presencia del encomendero que, según los testigos del documento, se servía de su influencia sobre los indígenas de Atacama para impedir que el nuevo corregidor asumiera su cargo. Velázquez Altamirano tenía bajo su control una red de extracción, transporte, almacenamiento y comercialización de pescado que no pretendía abandonar (Martínez 1985b).

Al parecer, el principal motivo de descontento entre los españoles por la hegemonía de Velázquez Altamirano estaba justamente en la monopolización de la mano de obra indígena local, que le permitía adjudicarse una parte de la producción marina y su posterior venta en el mercado potosino.

Las labores extractivas y el transporte de la mercancía estaban en manos del encomendero, quien tenía 
distribuida a su familia entre Cobija y Chiu Chiu con el fin de controlar y administrar esta actividad.

Los atacamas eran quienes estaban a cargo del transporte del pescado y, aunque no se explicita en el texto del documento, eran seguramente los camanchacas quienes realizaban las faenas pesqueras. Es probable que ya en 1591 este grupo costero haya estado tributando en pescado como lo hizo durante el siglo XVII (AGI n 92 1644, f. 71v.).

\section{El transporte desde la costa a Chiu Chiu}

Desde Cobija, el pescado era llevado a Chiu Chiu donde se almacenaba para ser enviado posteriormente a Potosí.

“... a uisto ocuparse muchos indios de la mar ques el puerto de la Madela [sic] de Cobija distrito deste dicho corregimiento hasta Chiuchio i hasta Potosí sacarles los indios atacamas el pescado a cuestas como lo hicieron el año pasado dicho por el i por sus hijos i que agora al presente le han sacado los dichos yndios maior cantidad de pescado i que lo tienen en estos pueblos de Atacama para llebar a Potosí y que sane que ay hasta donde lo traen a cuesta bentiocho o treinta leguas i questo lo sane porque lo a andado dos ueces i en el a topado mucha cantidad de indios cargados con el dicho pescado..." (Martínez 1985b).

Llama la atención el hecho de que no se utilizaban llamas en el trayecto de Cobija a los oasis. Sabemos que en Atacama había ganado en abundancia. Sin embargo, las características de extrema aridez que presenta el litoral atacameño, nos llevan a preguntarnos si era posible trasladarse allí con las recuas de llamas y, por consiguiente, si el trayecto de Cobija al interior constituía una ruta de caravanas antes de la llegada de los españoles.

El litoral del norte chileno se caracteriza por su condición extremadamente desértica. Sin embargo, esto no había impedido que desde épocas muy tempranas los pueblos que ocupaban los oasis del interior y las tierras altas, aprovecharan cada ruta y cada nicho que les permitiera acceder a los recursos del mar.

Las regiones costeras más fértiles y que ofrecían recursos forrajeros permanentes o semipermanentes para las caravanas se distribuían desde el sur de Perú hasta algo más allá de Iquique. A partir de allí, salvo puntos muy localizados, se extendía el desierto costero.
Los asentamientos arqueológicos son más dispersos y denotan presencias mucho menos estables de lo que se da más al norte. Sólo algunos presentan rasgos agropecuarios como Tocopilla, algunos puntos del sur de Iquique y la desembocadura del río Loa. Esta última ofrecía la posibilidad de una presencia más permanente, y fue ocupada y explotada por gente del interior proveniente de la zona del Loa Medio y de los oasis de Tarapacá. Además, se ha demostrado la existencia de contactos de los pobladores de los oasis atacameños con oasis costeros bastante alejados, como Taltal y Pisagua, hacia donde, siguiendo rutas provistas de agua, podían desplazarse con recuas de llamas (Núñez 1976: 189, 194; Núñez y Dillehay 1979: 68-69).

Al sur del Loa, los enclaves productivos y extractivos se limitan a algunas vertientes de agua, a veces semisalada, como es el caso de Cobija, que impedían reproducir el sistema de "islas" que presentan más al norte. A pesar de las precarias condiciones de este lugar, no estaba del todo desprovisto de forraje, como lo demuestra el hecho de que el tráfico con mulas haya podido desarrollarse posteriormente. Estacionalmente, podía encontrarse en los alrededores de Cobija alimento para las bestias, en los llamados "tiempos de lomas", que eran períodos en que brotaban pastos tiernos en los cerros del litoral desértico. Los desplazamientos en grandes caravanas de llamas que se producían en las costas fértiles de las regiones de Arica y sur de Perú se daban justamente en esas fechas (Murra 1975: 119). Por lo tanto, la ensenada de Cobija reunía condiciones para mantener allí algo de ganado temporalmente. Pero, el principal obstáculo para desplazarse con llamas estaba sobre todo en las características del trayecto para acceder a ella.

\section{La ruta a Cobija}

Tomando como referencia la distancia entre el oasis de Calama y la costa de Cobija, el recorrido, según las relaciones hechas por viajeros, funcionarios coloniales y republicanos, era de 38 a 40 leguas aproximadamente. Este trayecto, sin duda el más directo, se hacía -siguiendo los hitos Calama, Huacate, Chacance, Cobija- en tres o cuatro jornadas cuando se introdujeron las mulas, lo que con llamas hubiera significado un tiempo más prolongado. El último transecto (Chacance-Cobija) era sin duda el más penoso. Se trataba, según los testimonios, de aproximadamente $80 \mathrm{~km}$ desprovistos de agua. Sin embargo, algunos viajeros mencionan la posibilidad 
de encontrar agua en algunos puntos del recorrido en "tiempos de lomas" (Sanhueza Ms-a: 58-59).

No es extraño, entonces, que esta parte de la ruta se hiciese en el siglo XVI sin animales. Si bien los factores tiempo y distancia no eran determinantes para impedir el acceso de caravanas, dado que las llamas pueden recorrer distancias mucho mayores, sí parecen haberlo sido las condiciones de la ruta que implicaban un costo demasiado alto para los rebaños. ¿Fue el encomendero de Atacama el que impuso este trayecto? La línea recta que se traza entre la última posta con agua (Chacance) y el puerto, y la relativa centralización de las actividades pesqueras en ese enclave, nos parecen un producto netamente colonial. La desembocadura del Loa, que ofrecía un potencial forrajero y agrícola considerable para las condiciones de la región y que consecuentemente había sido explotada por la población de Atacama, quedaba fuera de la jurisdicción de ese corregimiento.

Probablemente, en tiempos prehispánicos, los atacamas accedían sólo estacional o excepcionalmente a la ensenada de Cobija, cuando se daban las condiciones para el desplazamiento. A partir del siglo XVI, la presión mercantil colonial que imponía la lógica de la rapidez y la rentabilidad, junto a la nueva $-\mathrm{y}$ en este caso incoherente- distribución espacial de las jurisdicciones administrativas, sometió a los indígenas a este circuito.

\section{El transporte a Potosí}

En los oasis del Loa, especialmente en Chiu Chiu, el pescado era almacenado y luego enviado por el encomendero en recuas de llamas hacia Potosí:

“... dixo que a oido decir que a tratado i contratado del puerto de la Madalena a Potosí distrito deste corregimiento i que estando este testigo en la prouincia de los lipis a uisto pasar por ella pescado i preguntando este testigo cuio era dice que le dixeron los indios quera del dicho Joan Velázquez Altamirano i que uiniendo a este pueblo de Atacama la Grande encontró en el camino tres indios deste dicho repartimiento que uenian con ganado del dicho Joan Velázquez Altamirano los quales dixeron a este testigo como auia mas de tres meses que auian salido de su tiera i que todo el dicho tiempo se auian ocupado en el seruicio del dicho Joan Velázquez Altamirano y que auian pasado mucha necesidad y la pasaban al presente de comida..." (Martínez 1985b: 168)
Según el testimonio, no sólo el pescado sino también el ganado de carga que esos indígenas llevaban, pertenecían al encomendero. Como es sabido, la apropiación de llamas para el transporte de mercaderías, por parte de los corregidores y en general de los comerciantes españoles, fue un hecho común durante el siglo XVI, incluso cuando ya la mula comenzaba a utilizarse en algunos circuitos. Las caravanas de llamas resultaban muy rentables, sobre todo en la región altiplánica, que constituía uno de los trayectos más extensos y más concurridos durante este período. Por eso los españoles recurrían al "rescate" o a la misma encomienda para adquirir carneros de la tierra y aumentar así el tráfico de sus mercaderías. Los comerciantes, y sobre todo los corregidores propietarios de ganado, que disponían de mano de obra indígena, podían desempeñarse en algunos casos como intermediarios, comprando mercadería en los centros productivos para luego comercializarla en Potosí, o como empresarios "fleteros" que se especializaban sólo en asegurar su transporte (Glave 1983). Otros monopolizaban todo el circuito: producción, transporte y puesta en mercado. Este es el caso de Velázquez Altamirano en Atacama. Su calidad de encomendero le permitía adjudicarse parte de la producción marina y de la energía humana necesaria para ella y su transporte, proporcionando él mismo los animales de carga y manejando, a la vez, la comercialización.

\section{Los arrieros de Atacama. El sistema de servicio personal}

Dentro de este contexto, la situación de los indígenas que realizaban los fletes, era extremadamente penosa. Además, estas "contrataciones" no se efectuaban entre el empresario y los individuos, sino entre este y las comunidades indígenas a través de la persona del cacique, quien debía responder con la mano de obra necesaria según las circunstancias. El tributo, que por esa época era señalado globalmente para cada repartimiento, caía bajo la responsabilidad exclusiva de los caciques y estos debían regular, al interior de la comunidad, la forma de pagarlo.

En ese sentido, Velázquez Altamirano se encontraba en una situación muy ventajosa que le permitía presionar sobre el entonces cacique principal, don Pedro Liquitaya, quien hacía las veces de mediador entre los indígenas y el encomendero. Según el documento, los arrieros de Atacama no percibían salario alguno por el flete de la mercadería a Potosí y, como el mismo cacique lo aseguraba, este se 
deducía del tributo anual, puesto que se les pagaba “...descontándoles los jornales en su tasa” (Martínez 1985b: 168).

Estos primeros arrieros funcionaban aún dentro de un sistema de prestación personal de servicios, modalidad que a pesar de sus intentos, las autoridades españolas no habían logrado erradicar. En definitiva, se utilizaba la fuerza de trabajo indígena bajo el alero de la obligación tributaria, para transportar la mercancía -prácticamente sin costos para el empresario- y, aparentemente, manteniendo a los arrieros al margen de las ganancias monetarias de dicha comercialización.

Sin embargo, a pesar del monopolio que Velázquez Altamirano ejercía sobre una parte de los recursos y mano de obra del corregimiento de Atacama, los indígenas, evidentemente, complementaban los trajines del encomendero con sus desplazamientos tradicionales. Si bien es indudable la actitud coercitiva del corregidor-encomendero, debemos considerar que el tráfico interregional no significaba un elemento novedoso dentro de las estrategias de supervivencia de los habitantes del desierto.

\section{El mercado indígena de Potosí y el intercambio interregional en el siglo XVI}

Si bien las exigencias del nuevo sistema políticoeconómico golpeaban fuertemente a la población indígena, el incentivo o la compulsión al desplazamiento hacia los nuevos mercados, permitía y reforzaba la reproducción de la movilidad y de las relaciones de complementariedad interregional. Esta situación, válida para todo el Período Colonial, se puede percibir en el caso de Atacama y sus regiones aledañas a partir de nuestras primeras informaciones.

Potosí, el más importante centro urbano y minero del Virreinato del Perú, era una importante plaza de comercio e intercambio no sólo hispano y mestizo, sino también indígena. Una gran variedad de productos provenientes de diferentes regiones, satisfacían la creciente demanda de los indígenas sometidos a la mita potosina y de aquellos que llegaban exclusivamente a realizar sus transacciones. Entre los principales productos de consumo e intercambio estaban el ganado de la tierra, el maíz, la coca, el pimiento, la chicha, la quínoa, el pescado seco, además de materias primas, textiles y manufacturas en general (Capoche 1959 [1583]: 129). Estos productos eran intercambiados por diferentes especies o por metales. La plata, a pesar de las protestas de los mineros españoles, fue rápidamente incorporada por los indígenas como objeto de venta e intercambio:

"Desde el descubrimiento y fundación de Potosí, ha sido costumbre muy guardada, entre los naturales, de tratar y contratar con libertad en los metales, vendiéndolos en plaza pública (que solo para este ministerio tienen señalada) en la cual se junta gran concurso de indios e indias a vender los que han adquirido o sacado, y otros a comprarlo..." (Capoche 1959 [1583]: 150).

En este movimiento de productos regionales y de metales, participaba una gran diversidad de grupos étnicos. Desde la circumpuna, lipes y atacamas, y probablemente también otros grupos, se integraron a ese mercado.

El caso de los indígenas de lipes nos parece interesante de mencionar. Los lipes, en cuya región se desarrolló tempranamente la actividad minera colonial, se alquilaban como mano de obra o explotaban directamente algunas vetas locales. Por este motivo, quedaron exentos de la mita minera de Potosí. Sin embargo, participaban activamente en las transacciones de productos y metales en ese mercado. El intercambio, dentro de sus estrategias de acceso a recursos complementarios, era uno de los principales mecanismos de adquisición de bienes como el maíz y la coca que, en sus tierras puneñas no podían producir. El ganado, que constituía una de sus principales riquezas, era llevado al mercado potosino y a las regiones del desierto:

“... porque siendo gente rica de ganados de la tierra y que cogen y siembran, y tienen contrataciones y rescates en esta villa de Potosí, Tarapacá y Atacama" (Lozano Machuca 1885 [1581]: XXIII).

Así como otros productos y recursos locales que eran de alta estima entre la población indígena que mitaba en los centros mineros:

“... vienen a vender un genero de ropa que allá hacen, y harina de quínoa, y colores y plumería de muchos avestruces que se crían en su tierra" (Capoche 1959 [1583]: 129).

La explotación de minas en su región les permitía además realizar transacciones por metálico en Potosí. Entre los productos así adquiridos, la coca parece haber alcanzado un lugar preponderante: 
“... son extremadamente viciosos en comer coca y tienen de gasto ordinario della cada año mas de diez mili pesos ensayados, porque todo el rescate que tienen en esta villa de Potosí es llevar coca solamente a su tierra..." (Lozano Machuca 1885 [1581]: XXIV).

Estas grandes cantidades de coca se utilizaban, al parecer, no sólo para el autoconsumo sino también para intercambiarla en su región y en las tierras bajas por otros productos. Aunque tardías, diversas fuentes de información manifiestan este procedimiento. En 1712, por ejemplo, el cura párroco de Casabindo y Cochinoca, con la intención de establecer una pulpería, decidía enviar a los indígenas de su doctrina con ganado vacuno a diferentes lugares para intercambiarlo por los productos que éstos podían ofrecer:

“... tengo pensado embiar a lipes unas vacas por coca otras a Tarixa por mais otras a Sinti por bino y aguardiente, otros a Jujuy por yerua, y de estos géneros y otras inmundicias armar mi pulpería..." (AGNA, Doctos Diversos, L. 11, 1712, f. 395).

Aunque en Lípez no se cultivaba coca, este sacerdote que aparentemente conocía bien las regiones vecinas y sus recursos, la enviaba a buscar allí.

Los lipes, que continuamente se desplazaban hacia las tierras y valles bajos, intercambiaban también sus excedentes de coca en los oasis de Atacama. En el siglo XIX, Bertrand describía las actividades de los pastores del suroeste boliviano, quienes viajaban desde sus aldeas hacia Tupiza (Chichas), Esmoraca y Santa Catalina (Puna de Jujuy), con su ganado de llamas y sus tejidos,

“... trayendo en retorno cargas de coca que venden a buen precio a los pastores indígenas y que aun introducen de contrabando a Atacama" (Bertrand 1885: 70).

Al comenzar este siglo, los indígenas de San Cristóbal de Lípez, continuaban trayendo -entre otras especies- hojas de coca que intercambiaban en San Pedro de Atacama, por productos tradicionales como la chicha y los frutos del chañar (Risopatrón 1918 [1903]: 157).

Es posible, entonces, que estos hombres de la Puna hayan podido funcionar, en gran medida, como proveedores e intermediarios en los circuitos de la coca a través de todo el Período Colonial y Republicano. Esta red de circulación probablemente prehispánica, logró adaptarse al sistema colonial articulando formas de intercambio mercantil y tradicional.

La población de los oasis de Atacama, por otra parte, acudía regularmente a las tierras altas y, desde el Período Colonial Temprano, a los centros mineros. Como arrieros del encomendero, complementaban sus labores de flete con el transporte de sus propios excedentes agrícolas, ganaderos e incluso marinos.

Los atacamas encomendados a Velázquez Altamirano viajaban constantemente a Potosí, Porco y La Plata, donde incluso residían por algunos períodos:

“... los caciques principales e indios después que están encomendados en el dicho Joan Velázquez Altamirano an uenido y bienen a esta ciudad ( La Plata) e prouincia a sus contrataciones $i$ este testigo a hablado ansi en Porco como en Potosi muchas vezes a dichos caciques e indios" (AGI 1596, 69v).

“... i que los dichos indios tienen sus tratos en esta prouincia y van y vienen y residen algunos de ellos en ella..." (AGI 1596, f. 58).

Estas rutas y circuitos mercantiles, involucraban regiones y grupos tradicionalmente vinculados a los habitantes del desierto. La ruta a Potosí, que atravesaba la Puna y minas de Lípez, permitía a los arrieros de Atacama abastecerse e intercambiar productos, así como adquirir metales.

Con el Noroeste Argentino, la gente de Atacama continuaba practicando el intercambio y se proveía allí de ganado, minerales y probablemente de productos agrícolas. En 1581, por ejemplo, el Factor de Potosí proponía - con la finalidad de pacificar la región de los omaguacas y casabindos-utilizar los conocimientos que de ellos tenían los atacamas:

“... y con estos indios atacamas y cien españoles se podría conquistar toda la tierra de omaguaca, questá cuarenta leguas de Atacama y se tratan y tienen rescate entre ellos de oro y plata y saben toda la tierra, y los omaguacas es poca gente y tienen mucho ganado y mucho oro y plata" (Lozano Machuca 1885 [1581]: XXIV). 
Sabemos además que los atacamas explotaban directamente ciertos recursos en esa región, lo que permitía, además de diversificar su producción, dinamizar el intercambio con otros grupos locales y el desplazamiento a los centros mineros. Lozano Machuca hace referencia a un grupo de indios "cimarrones", a quienes no identifica étnicamente, que estaban ubicados al sur del corregimiento de Lípez, los cuales no estaban aún sometidos a tributación ni habían sido adoctrinados:

“... hay otros indios que confinan con los indios de guerra de omaguacas y casabindo, y tienen trato y comercio con estos lipes, los cuales están neutrales, que no son de paz ni de guerra, y entran en Potosí con nombre de indios lipes y atacamas con ganados y otras cosas de venta y rescate..." (Lozano Machuca 1885 [1581]: XXIV).

Es probable que la confusión del cronista se deba a una errada percepción de la distribución territorial de atacamas y lipes, a quienes él situaba exclusivamente en los corregimientos correspondientes. Es posible también, como se ha planteado, que los estrechos vínculos entre estos diversos grupos regionales, permitieran que unos se atribuyeran el nombre de otros con una finalidad específica, como sería en este caso, el poder acceder al mercado potosino (Martínez 1990). Se trate de atacamas, lipes o un tercer grupo, nos interesa destacar que aún sin estar encomendados y, por tanto, sin la presión del tributo sobre ellos, acudían por su propia iniciativa a las plazas de Potosí a comerciar e intercambiar sus productos.

La red de relaciones socioeconómicas entre diferentes etnias o grupos regionales, permitió articular sus circuitos tradicionales con el desplazamiento a los centros mercantiles. En Atacama, a pesar de las transformaciones que comenzaban a producirse, y de las presiones y abusos de corregidores y encomenderos, el tráfico caravanero continuaba desenvolviéndose y complementaba las transacciones de tipo mercantil con el intercambio.

En este contexto, el ganado camélido era un elemento fundamental para la circulación interregional, no sólo como objeto de intercambio sino como medio de transporte de carga para indígenas y españoles. Por ello, la tecnología ganadera tradicional -con su consiguiente organización socioproductivadesarrollada por las poblaciones de la Subárea Circumpuneña, pudo ser otro de los pilares que facilitaron este proceso readaptativo.

\section{Tráfico y tecnología ganadera: Socialización de los recursos}

La crianza masiva de la llama y la necesidad de su domesticación para la carga y el desplazamiento, requerían del desarrollo de una tecnología adecuada. Entendemos por esta, no sólo las técnicas vinculadas con el tráfico, sino también las relaciones sociales y económicas que le están asociadas y que permiten su aplicación y reproducción.

El ganado constituía un bien de primera importancia tanto económica como socialmente. La crianza de llamas, no sólo permitía asegurar una fuente directa de alimentación, un medio de desplazamiento o un producto trocable, sino también un recurso de inserción de la unidad doméstica dentro de una estructura social compleja, sustentada en una serie de relaciones de reciprocidad institucionalizada (Alberti y Mayer 1974; Murra 1975: 124).

Las relaciones sociales de producción en las sociedades andinas se fundaban principalmente en el parentesco. De ahí que también fueran los vínculos de parentesco los que aseguraran a cada unidad doméstica, en sus inicios, la adquisición de ganado. La herencia, los regalos asociados a determinados ceremoniales durante la infancia y adolescencia y, sobre todo el matrimonio, eran los mecanismos a través de los cuales un individuo accedía no sólo a animales, sino también al derecho de usufructuar de los recursos de sus parientes y de la comunidad. Estos derechos implicaban, a su vez, responsabilidades y obligaciones hacia los demás, que involucraban actividades de construcción, el trabajo de la tierra y el cuidado del ganado (Murra 1975: 126).

El ganado en la actualidad es de propiedad individual o familiar. Probablemente también lo era al iniciarse la colonia. Existía también ganado perteneciente a la comunidad. Esta forma se ha registrado en las sociedades altiplánicas del siglo XVI y es posible que constituyera una modalidad común a otras regiones.

El cuidado del ganado familiar estaba a cargo de cada unidad doméstica y, al menos actualmente, ejercen esta labor los niños y las mujeres, sobre todo en aquellas comunidades donde el tráfico de caravanas se mantiene, por ser los hombres los que realizan los viajes (Flores Ochoa 1977: 139). 
El pastoreo no precisaba de mano de obra muy abundante. Sin embargo, requería de una disponibilidad constante durante todo el año. Por ello era necesario distribuir y organizar las labores, de tal manera que quienes tuvieran a su cargo el cuidado del ganado en la puna, contaran con el trabajo de los otros miembros de su unidad familiar o de su comunidad para el cultivo de sus chacras u otras actividades. Los viajes a grandes distancias podían durar varios meses y requerían, a su vez, de la cooperación de los parientes.

No sabemos si existía algún tipo de especialización social en esta actividad. Salvo excepciones, en las comunidades actuales son los hombres quienes la realizan y el proceso de aprendizaje comienza desde la niñez.

Podemos distinguir ciertas técnicas pastoriles especializadas para el caravaneo: la domesticación de los animales para el desplazamiento con carga, el "machaje" que consiste en la separación de los machos cargueros respecto de las hembras y, en ciertas regiones, el "capado" de los machos de carga (Sanhueza 1991: 35-36).

A estas modalidades se sumaba el indispensable manejo de pastizales ubicados a distintas alturas. En un medio de características tan extremas, la alimentación y reproducción del ganado dependía de la optimización del manejo de los pastos o vegas naturales. Aunque el forraje puneño es permanente, su utilización era estacional, dadas las bajas temperaturas que se registran en invierno. Ello implicaba un desplazamiento transhumántico tierras altas-tierras bajas de acuerdo a los ciclos calendáricos.

Por otra parte, la dispersión de los pastos naturales y su uso diferenciado, según los niveles altitudinales, requerían de un sistema de asentamiento que permitiera esa flexibilidad. En la actualidad, las comunidades agropastoriles andinas, y específicamente las de Atacama, se caracterizan por mantener un patrón de poblamiento disperso y complementario, que alterna la residencia en núcleos poblacionales más permanentes con la ocupación temporal de viviendas o estructuras habitacionales llamadas "estancias", diseminadas en torno a las fuentes de agua y pastos de altura (Aldunate y Castro 1981: 40-43).

El desarrollo de la movilidad ganadera habría permitido, sobre todo en períodos prehispánicos, la articulación del manejo de recursos forrajeros distantes con la circulación y el intercambio de excedentes productivos (Núñez y Dillehay 1979: 4). En este sentido, la actividad ganadera se complementaba con la práctica del intercambio, asegurando, a su vez, la reproducción del ganado. Los asentamientos de altura constituían un puente de acceso y de contactos con otros ambientes y otros grupos.

Los pastos o vegas naturales parecen haber sido de usufructo colectivo. Eso no significa, sin embargo, que su utilización fuera indiscriminada. La etnografía nos entrega algunos elementos importantes de considerar.

Para las comunidades de Atacama, si bien los pastizales tienen un carácter colectivo, su explotación está supeditada a un "orden" establecido que regula los derechos de acceso. Un grupo familiar o una comunidad determinada no pueden utilizar indistintamente cualquier vega para alimentar su ganado, a la vez que cada nicho forrajero suele estar sectorizado, distribuyéndose en él los espacios a ocupar por cada familia. Por otra parte, existen pastizales que son explotados exclusivamente por los miembros de una comunidad, y otros de carácter intercomunitario, es decir, que se utilizan por más de un pueblo o comunidad sin que ello genere conflictos (Serracino y Stehberg 1975: 89; Aldunate y Castro 1981; Folla 1989).

Nos encontramos en la actualidad con una diversidad de mecanismos sociales que determinan el derecho de acceso a estos recursos. Ello constituye un referente importante para abordar algunos aspectos tecnológicos de la actividad arriera colonial en Atacama.

Cabe preguntarse, por ejemplo, cómo se distribuían al interior de un mismo grupo étnico, sus parcialidades o sus ayllu los derechos de uso.

Durante los siglos XVII y XVIII los documentos mencionan de modo constante la importancia de los "pastos del común" para los arrieros de Atacama. Incluso, cuando ya el ganado mular había prácticamente desplazado al camélido en esta actividad, la posibilidad de utilización de las vegas locales (de tierras bajas y altas) fue un factor fundamental para el desarrollo de la arriería indígena. El derecho a alimentar y engordar el ganado -antes y después de cada travesía- no representaba "gastos suplementarios" para los originarios de Atacama (Sanhueza 1991: 87-95). 
Sabemos también, en base a información etnohistórica, que había en el mundo andino sectores de pastizales utilizados en forma multiétnica (Murra 1975: 67). Por tanto, más allá de las variables estrictamente locales, existían ciertos principios o acuerdos colectivos que permitían el manejo, probablemente sectorizado, de determinados nichos forrajeros por más de un grupo étnico.

Son sugerentes en este sentido los datos entregados por la documentación de los siglos XVII y XVIII. Tenemos abundantes referencias del desplazamiento de tributarios de Atacama hacia distintas localidades de los corregimientos de Lípez y Tucumán, donde se dedicaban a actividades mineras, agrícolas y ganaderas (Hidalgo 1984; Martínez et al. 1988). En la Revisita efectuada a Atacama en 1683, se establecía que un alto porcentaje de la población de Atacama se encontraba fuera del corregimiento. Sólo en algunos casos el documento menciona las localidades específicas donde se encontraban los tributarios ausentes y, en menos aún, se describe el tipo de actividad que estaban realizando. Excepcionalmente, en el ayllu de Solor de Atacama La Alta se registra el caso de tres tributarios dedicados a actividades ganaderas. Dos de ellos se encontraban en el río San León (Lípez) y uno en el río de San Juan (Tucumán), los que se habrían desplazado a esos lugares "por la comodidad de los pastos para sus ganados" (AGNA S. IX, L. 7-7-1, f. 22v.). Estos atacameños seguían tributando en su ayllu de origen.

Por su parte, la revisita realizada al corregimiento de Lípez en 1689 proporciona algunos antecedentes interesantes. Como se describe en sus páginas, el sistema de poblamiento disperso permitía también a sus habitantes mantener una importante masa ganadera, tanto de origen europeo como autóctono. De acuerdo a los datos de esa revisita, los lipes declaraban tener, sólo en "ganado de la tierra", aproximadamente 6000 cabezas. Sin embargo, según las autoridades indígenas locales, más de 2000 animales pertenecían a forasteros provenientes de distintas provincias y corregimientos, quienes los mantenían en las vegas de los alrededores de San Cristóbal de Lípez. El derecho a utilizar estos pastos era reconocido por los gobernadores y caciques lipes (AGNA S. XIII L. 23-10-2, f. 117v.). Entre estos forasteros se mencionaba a un originario de Atacama La Alta, Juan Catacata, desgraciadamente sin proporcionar más información.
En el corregimiento de Tucumán, por otro lado, en la localidad del río de San Juan -ubicada en la zona fronteriza de este corregimiento con los de Lípez y Chichas- la revisita de 1683 registraba, como dijimos, sólo a un tributario de Atacama realizando allí actividades ganaderas "por la comodidad de sus pastos". Sin embargo, la misma revisita establece que un número muy significativo de atacameños tributarios se encontraba ausente por períodos breves o por años en ese lugar, pero en ninguno de ellos, salvo en el caso indicado, se entrega más información. Este paraje parece haber sido un verdadero enclave atacameño, no sólo por su potencial forrajero sino también como fuente de abastecimiento de otros recursos. Por la misma fecha de esa revisita, según otra fuente, el corregidor de Atacama, ávido de mano de obra para sus minas, debía salir acompañado del cacique de Atacama La Alta en busca de sus tributarios

“... al rio de San Juan adonde tiene su asistencia la mayor parte de la gente de esta provincia de Atacama y el dicho paraje es jurisdicción de la provincia de Tucuman..." (ANB Exp. Col. E $\mathrm{n}^{\circ} 2451,1683$, f. 131).

Por lo tanto, la cantidad de atacameños que utilizaban los pastos de esa localidad, debe haber sido mucho más importante de lo que refleja la revisita.

El río de San Juan, por otra parte, no sólo constituía un enclave de explotación directa para la gente de Atacama, sino también, por su ubicación, permitía mantener relaciones continuas con los lipes y con centros productivos coloniales, en 1712, se lo definía en un documento como el río "de los atacamas":

“... el rio de San Juan de los atacamas que asisten alli por el trato sercano que tienen para lipes y los minerales del asiento de San Joseph de la rinconada santa catalina la cruz y la concepción y varias estancias de españoles..." (AGNA, Doctos Diversos, L. 11, 1712, f. 398).

De tal manera que, aunque no nos es posible determinar con claridad cómo se distribuían en ese espacio los distintos grupos étnicos que lo habitaban, ni si se compartían efectivamente ciertos nichos productivos, al menos podemos afirmar que este asentamiento atacameño se localizaba en un área de interacción multiétnica. 
En este contexto general, la actividad ganadera parece insertarse en un macroespacio que permitía la reproducción de la actividad arriera mercantil, de acuerdo a pautas sociales y económicas andinas.

A modo de conclusión, la arriería indígena en Atacama surgió como un medio de inserción en el sistema económico que comenzaba a desarrollarse en el siglo XVI.

Por una parte constituyó un mecanismo de presión del aparato colonial para mercantilizar la producción y circulación de productos locales y adquirir mano de obra indígena.

La región de Atacama, dadas sus condiciones ecológicas que no permitían una alta productividad -de acuerdo a los intereses de una economía mercantilllevó a los españoles a crear determinadas fórmulas de apropiación y acumulación de bienes. El fomento de la actividad arriera, a través del servicio personal, aseguraba la realización comercial -a muy bajos costos- de productos controlados por corregidores $\mathrm{y}$ encomenderos.

El sistema colonial implantó un determinado ordenamiento del espacio a nivel político-administrativo y económico. Sin embargo, la Subárea Circumpuneña, como espacio social, continuó funcionando para la población indígena.

A pesar de las tensiones que la arriería, como fenómeno global, pudo provocar en ella, la población de Atacama del siglo XVI integró esta actividad a sus estrategias andinas, reproduciendo sus patrones de movilidad caravanera y sus circuitos de tráfico interregional.

Articulando racionalidades económicas diferentes, los arrieros combinaron el intercambio y el comercio, formas de propiedad colectiva de recursos y reciprocidad comunitaria, con la prestación de energía para el pago del tributo y el desplazamiento a los mercados mineros.

\section{REFERENCIAS CITADAS}

\section{Fuentes inéditas}

Archivo General de Indias (AGI).

Charcas, Legajo 80, año 1596, fol. 3: Probanza de Juan Velázquez Altamirano, corregidor de Atacama y de su hijo Francisco Altamirano. $120 \mathrm{fs}$.

Charcas, Legajo 92, año 1644. Probanza de Francisco de Otal. $105 \mathrm{fs}$.

Justicia, Legajo 405 B n 2 Ramo 1563 "Lucas Martínez Vegazo, alcalde de la ciudad de Arequipa con Juan de Castro de la misma vecindad, sobre deshacer el contrato de permuta de los indios de Cochuma con los de Pica". 157 fs.

Archivo Nacional de Bolivia (ANB)

Sección Expedientes coloniales

E $n^{\circ}$ 2451, año 1683 "Residencia tomada a Don Antonio Gutiérrez Caro del tiempo en que fue corregidor del Partido de Atacama". $166 \mathrm{fs}$

\section{Archivo General de la Nación (AGNA)}

Sala IX

Legajo 7-7-1, Colonia-Gobierno, Atacama, varios padrones 1683-1777: Padrón de Atacama, año 1683. 52 fs.

Sala XIII

Legajo 23-10-2 Contaduría de Potosí, varios padrones 1611-1690, Padrón de los indios lipes, año 1689. 200 fs.
Documentos Diversos

Sección Colonia, Serie VI, Legajo 11, Casabindo y Cochinoca, 1655-1855, año 1712: "Testimonio de los autos seguidos contra el Doctor Don Fernando de Herrera cura que fue de Casavindo y Cochinoca y su ayudante Don Simón de Abalos por los curacas de aquel pueblo y el Marques del Tojo". 84 fs.

\section{Publicaciones}

ALBERTI, G. y E. MAYER (Comps.), 1974. Reciprocidad $e$ intercambio en los Andes peruanos. Instituto de Estudios Peruanos, Lima.

ALDUNATE, C. y V. CASTRO, 1981. Las Chullpa de Toconce y su relación con el poblamiento altiplánico en el Loa Superior. Período Tardío. Ediciones Kultrún, Santiago.

ASSADOURIAN, C. S., 1982. El sistema de la economía colonial. Mercado interno, regiones y espacio económico. Instituto de Estudios Peruanos, Lima.

BERENGUER, J., 1984. San Pedro de Atacama. Espacio, tiempo, y cultura. En Tesoros de San Pedro de Atacama. Museo Chileno de Arte Precolombino, Santiago.

BERTRAND, A., 1885. Memoria sobre las cordilleras del Desierto de Atacama y regiones limítrofes. Imprenta Nacional, Santiago.

BIBAR, G. DE, 1966 [1558]. Crónica y relación copiosa y verdadera de los reinos de Chile... Fondo Histórico y Bibliográfico J. T. Medina, vol. 2, Santiago. 
CAPOCHE, L., 1959 [1583]. Relación general de la Villa Imperial de Potosí. Biblioteca de Autores Españoles, vol. 122. Madrid.

CASASSAS, J. M., 1974. La región atacameña en el siglo XVII. Universidad del Norte, Antofagasta.

CASTRO, V., C. ALDUNATE y J. BERENGUER, 1984. Orígenes altiplánicos de la Fase Toconce. Estudios Atacameños 7: 209-235

FLORES OCHOA, J. (Ed.), 1977. Pastores de Puna, uiwamichiq puna-runakuna. Instituto de Estudios Peruanos, Lima.

FOLLA, J. C., 1989. Anthropologie économique d'une communauté paysanne du Desert d'Atacama: Socaire. Memoire de Maitrise Département d'Anthropologie, Université de Montréal, Montreal.

GLAVE, L. M., 1983. Trajines. Un capítulo en la formación del mercado interno colonial. Revista Andina 1: 9-67.

GUNDERMANN, H., 1984. Ganadería aymara, ecología y forrajes: Evaluación regional de una actividad productiva andina. Chungara 12: 99-123.

HIDALGO, J., 1984. Complementariedad ecológica y tributo en Atacama, 1683-1792. Estudios Atacameños 7: 422-442.

KRAPOVICKAS, P., 1978. Los indios de la Puna en el siglo XVI. Relaciones de la Sociedad Argentina de Antropología XII: 71-93.

LOZANO MACHUCA, J., 1885 [1581]. Carta del Factor de Potosí... al virrey del Perú, en donde se describe la provincia de los lipes. Relaciones Geográficas de Indias, Perú, vol. 2, Apéndice III, Madrid.

MARTINEZ, J. L., 1985a. Adaptación y cambio en los atacameños. Los inicios del Período Colonial. Siglos XVI y XVII. Andes 3: 9-25.

1985b (Ed.). Información sobre el comercio de pescado entre Cobija y Potosí, hecha por el corregidor de Atacama, don Juan de Segura (19 de julio de 1591). Cuadernos de Historia, pp. 161-171.

1990. Interetnicidad y complementariedad en el Altiplano Meridional. Andes 1: 11-30.

MARTINEZ, J. L., A. M. FARIAS, C. ODONE y P. BLAZQUE, 1988. Dispersión y movilidad en Atacama colonial. Encuentro de etnohistoriadores. Serie Nuevo Mundo. Cinco siglos 1: 53-69.

MURRA, J., 1975. Formaciones económicas y políticas en el mundo andino. Instituto de Estudios Peruanos, Lima,

NUÑEZ, L., 1976. Geoglifos y tráfico de caravanas en el desierto chileno. Anales de la Universidad del Norte 10: 147-201.

NUÑEZ, L. y T. DILLEHAY, 1979. Movilidad giratoria, armonía social y desarrollo en los Andes Meridionales: Patrones de tráfico e interacción económica (ensayo). Universidad del Norte, Antofagasta.

ODONE, C., 1991Ms. Tarapacá y el tejido de un registro. Ponencia presentada al Congreso de Arqueología Chilena, Temuco.

PALACIOS, F., 1981. Tecnología del pastoreo. En La tecnología en el mundo andino. Runakunap kawsayninkupaq rurasqankunaqa vol. 1: 217-232. Universidad Nacional Autónoma de México, México D. F.

PAZ SOLDAN, M. F., 1878. Verdaderos límites entre el Perú y Bolivia. Sección Documentos inéditos que comprueban el derecho del Perú, sobre parte de la costa y demás territorio usurpado por Bolivia, pp. 51-70, Lima.

PEASE, F., 1986. Apuntes sobre la etnohistoria peruana actual. En La cuestión rural en el Perú $2^{\mathrm{a}}$ edición, Lima.

PLATT, T., 1987. Calendarios tributarios e intervención mercantil. Racionalidades estacionales entre los indios de Lípez (Bolivia) en el siglo XIX. Chungara 19.

RISOPATRON, L., 1918. Diario de viaje a las cordilleras de Antofagasta y Bolivia (1903-1904). Revista Chilena de Historia y Geografía XXVII. Imprenta Universitaria, Santiago.

SALOMON, F., 1985. The dynamic potencial of the complementerity concept. En Andean ecology and civilization, S. Masuda, I. Shimada y C. Morris (Eds.), pp. $511-531$. Universidad de Tokio, Tokio.

SAIGNES, T., 1986. En busca del poblamiento étnico en los Andes bolivianos (siglos XV y XVI). Avances de Investigación 3 Museo Nacional de Etnografía y Folklore, La Paz.

SANCHEZ, S. y G. SICA, 1990. La frontera oriental de Humahuaca y sus relaciones con el Chaco. Bulletin de l'Institut Français d'Etudes Andines 19 (2): 469-497.

SANHUEZA, C. 1991. Orígenes y desarrollo de la arriería colonial en Atacama. Siglos XVI-XVII, Tesis de Licenciatura en Historia, Pontificia Universidad Católica de Chile, Santiago.

_ 1991Ms. Estrategias readaptativas en Atacama: La arriería mulera colonial. Ponencia presentada en el II Congreso Internacional de Etnohistoria, Coroico.

SERRACINO, G. y R. STEHBERG, 1975. Vida pastoril en la precordillera andina. Estudios Atacameños 3: 81-99.

TARRAGO, M., 1984. La historia de los pueblos circumpuneños en relación con el altiplano y los Andes Meridionales. Estudios Atacameños 7: 116-132.

VASQUEZ DE ESPINOZA, A., 1948 [1628]. Compendio y descripción de las Indias Occidentales. Smithsonian Institution, Washington D. C.

WATCHEL, N., 1973. Sociedad e ideología. Ensayos de Historia y antropología andinas. Instituto de Estudios Peruanos, Lima. 